\title{
SIMULASI TEGANGAN PROPELLER AI-Mg YANG DIRANCANG UNTUK PROPELLER RENDAH BISING
}

\author{
Yogi Adiansyah ${ }^{1}$, Ikhwansyah Isranuri ${ }^{2}$, Alfian Hamsi ${ }^{3}$, M. Sabri ${ }^{4}$, Bustami Syam ${ }^{5}$ \\ ${ }_{1,2,3,4,5}$ Departemen Teknik Mesin, Fakultas Teknik, Universitas Sumatera Utara \\ E-mail : aldiansyahyogi10@yahoo.co.id
}

\begin{abstract}
ABSTRAK
Salah satu bagian dari pesawat UAV adalah propeller, dimana fungsi propeller ini adalah sebagai gaya dorong (trush) bagi sebuah pesawat. namun dalam sebuah propeller terdapat gaya dorong yang menyebabkan terjadi beberapa macam tegangan yang terjadi propeller Untuk mempermudah mendapatkan tegangan, regangan dan deformasi yang terjadi pada bilah propeller maka dilakukan simulasi aliran maupun static structural yang merupakan tujuan dari penelitian ini. Kegunaan dilakukannya simulasi ini adalah untuk mendapatkan nilai tegangan, regangan dan deformasi yang terjadi pada setiap elemen propeller. Dalam hal ini setiap bagian pada propeller akan mendapatkan tegangan yang berbeda pada setiap titik. Dalam melakukan simulasi pada propeller peneliti menggunakan software ansys 15.0 yaitu fluent dan static structural dengan variasi kecepatan fluida sebesar $10-50 \mathrm{~m} / \mathrm{s}$. Propeller dibagi dalam 198827 meshing yang dilakukan di fluent, setelah hasil aliran didapat maka hasil tersebut menjadi input di uji static structural. Dari hasil uji static structural deformasi, tegangan dan regangan yang didapat pada kecepatan $10 \mathrm{~m} / \mathrm{s}$ sebesar $2.9742 \times 10^{-}$ ${ }^{7} \mathrm{~m}, 1.2676 \times 10^{-6} \mathrm{dan} 51.46 \mathrm{~Pa}$. pada kecepatan $20 \mathrm{~m} / \mathrm{s}$ sebesar $1.0941 \times 10^{-6} \mathrm{~m}, 4.6729 \times 10^{-6} \mathrm{dan}$ $19134 \mathrm{~Pa}$. pada kecepatan $30 \mathrm{~m} / \mathrm{s}$ sebesar $2.1874 \times 10^{-6} \mathrm{~m}, 9.3428 \times 10^{-6}$ dan $38322 \mathrm{~Pa}$. pada kecepatan $40 \mathrm{~m} / \mathrm{s}$ sebesar $3.5028 \times 10^{-6}, 3.5028 \times 10^{-6}$ dan $1.4962 \times 10^{-5}$.Pada kecepatan $50 \mathrm{~m} / \mathrm{s}$ sebesar $5.0521 \times 10^{-6}$ $\mathrm{m}, 2.1581 \times 10^{-5}$ dan $89077 \mathrm{~Pa}$. Hasil pengujian ini menunjukkan bahwa deformasi yang paling besar terjadi pada bilah propeller terletak pada bagian terluar propeller sedangkan regangan dan tegangan yang terjadi pada bilah propeller terletak pada bagian $h u b$ propeller.
\end{abstract}

Kata kunci : Propeller, fluent, static structural, meshing, tegangan propeller.

\section{PENDAhuluan}

Indonesia merupakan negara kepulauan yang sangat luas dengan luas seluruhnya $5.193 .250 \mathrm{~km}^{2}$, dan hampir dua pertiga wilayah Indonesia merupakan wilayah perairan dengan luas mencapai $3.287 .010 \mathrm{~km}^{2}$. Luas wilayah tersebut memiliki resiko tersendiri dari segi pengamanan wilayah teritorial. Hal tersebut menuntut pemerintah dan jajarannya ( baik pemerintah daerah, TNI, POLRI) mengeluarkan sumber daya yang banyak untuk menjaga dan keamanan wilayah kesatuan Negara Republik Indonesia. Berdasarkan kenyataan tersebut, sangat diperlukan untuk mengembangkan sebuah pesawat udara tanpa awak (Unmanned Aerial Vehicle atau disingkat UAV) yang bertujuan sebagai pendukung pertahanan keamanan nasional dan pengintaian. Hal ini diharapkan dapat menekan biaya dan sumber daya terhadap pengawasan pertahanan dan keamanan wilayah-wilayah Indonesia. Pesawat udara tanpa awak (Unmanned Aerial Vehicle) merupakan sebuah wahana terbang yang dikendalikan dari jarak jauh untuk melakukan misi tertentu. [2]

Salah satu bagian dari pesawat UAV adalah propeller, dimana fungsi propeller ini adalah sebagai gaya dorong (trush) bagi sebuah pesawat, namun dalam sebuah propeller terdapat gaya dorong yang menyebabkan terjadi beberapa macam tegangan yang terjadi propeller, untuk mengetahui hal tersebut maka dilakukan simulasi pada propeller untuk mengetahui 
tegangan yang terjadi pada bilah propeller dan dapat mendapatkan berapa besar tegangan, regangan dan deformasi yang terjadi pada setiap titik/elemen pada propeller.

\section{TINJAUAN PUSTAKA}

\section{Pesawat Tanpa Awak (UAV)}

Pesawat tanpa awak (UAV) adalah sebuah mesin terbang yang berfungsi dengan kendali jarak jauh oleh pilot atau mampu mengendalikan dirinya sendiri, menggunakan hukum aerodinamika untuk mengangkat dirinya, bisa di gunakan kembali dan mampu membawa muatan baik senjata maupun muatan lainnya. Penggunaan terbesar dari penggunaan pesawat ini adalah di bidang militer . Pesawat tanpa awak memiliki bentuk, ukuran, konfigurasi dan karakter bervariasi. Sejarah pesawat tanpa awak adalah drone, pesawat tanpa awak yang digunakan sebagai sasaran tembak. Perkembangan kontrol otomatis membuat pesawat sasaran tembak yang sederhana mampu merubah menjadi pesawat tampa awak yang kompleks.[2]

\section{Sistem Propulsi}

Setiap kendaraan membutuhkan sesuatu yang menghasilkan gerak,sesuatu yang mendorong kendaraan tersebut dan memberikan percepatan. Sistem propulsi merupakan mekanisme penggerak pada setiap pesawat udara. Gaya yang bekerja pada sistem propulsi merupakan penerapan dari hukum kedua Newton.[3]

\section{Gaya Yang Terjadi Pada Propeler}

Pada umumnya terdapat tiga jenis gaya yang terjadi pada saat sebuah propeler beroperasi. Berikut adalah gaya - gaya tersebut.

a. Thrust

Sebelum pesawat mulai bergerak, thrust harus digunakan. Pesawat akan tetap bergerak dan bertambah kecepatannya sampai thrust dan drag menjadi sama besar. Untuk menjaga kecepatan yang tetap maka thrust dan drag harus tetap sama, seperti halnya lift dan weight harus sama untuk mempertahankan ketinggian yang tetap dari pesawat. Jika dalam penerbangan yang datar (level), gaya thrust dikurangi, maka pesawat akan melambat. Selama thrust lebih kecil dari drag, maka pesawat akan terus melambat sampai kecepatan pesawat (airspeed) tidak sanggup lagi menahan pesawat di udara. Sebaliknya jika tenaga mesin ditambah, thrust akan menjadi lebih besar dari drag, pesawat terus menambah kecepatannya. Ketika drag sama dengan thrust, pesawat akan terbang dengan kecepatan yang tetap.[4]

b. Gaya Sentrifugal (Centrifugal Force)

Gaya sentrifugal disebabkan oleh gaya rotasi dari propeler dan cenderung untuk melempar baling - baling dari pusat, gaya sentrifugal merupakan gaya gerak melingkar yang berputar menjauhi pusat lingkaran dimana nilainya adalah positif

$$
\mathrm{Fs}=\mathrm{m} \mathrm{v}^{2} / \mathrm{r}
$$

Dimana :

$\mathrm{m}=$ massa

$\mathrm{v}=$ kecepatan semtrifugal

$\mathrm{r}=$ Jari - jari

c. Gaya Torsi atau Twist 
Analog rotational dari gaya, masa, dan percepatan adalah torsi, momen inersia dan percepatan angular Gaya yang bekerja pada lever, dikalikan dengan jarak dari titik tengah lever, adalah torsi. Contohnya, gaya dari tiga newton bekerja sepanjang dua meter dari titik tengah mengeluarkan torsi yang sama dengan satu newton bekerja sepanjang enam meter dari titik tengah. Ini menandakan bahwa gaya dalam sebuah sudut pada sudut yang tepat kepada lever lurus. Lebih umumnya, seseorang dapat mendefinisikan torsi sebagai perkalian silang.[1]

$$
\mathrm{T}=\mathrm{r} \times \mathrm{F}
$$

Dimana :

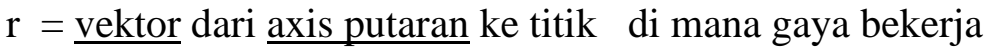

$\mathrm{F}=$ adalah vektor gaya

\section{Metode Elemen Hingga}

Metode elemen hingga merupakan salah satu metode numerik yang dapat di gunakan untuk menyelesaikan masalah struktural, thermal dan elektromagnetik. Dalam metode ini seluruh masalah yang kompleks seperti variasi bentuk, kondisi batas dan beban dapat di selesaikan dengan metode pendekatan. Karena keaneka ragaman dan fleksibilitas sebagai perangkat analisis, metode ini. Variabel dasar atau variabel medan yang tidak di ketahui yang di tentukan dalam masalah teknik adalah pergeseran dalam mekanik solid, kecepatan dalam mekanika fluida, potensial listrik dan magnet dalam teknik listrik dan suhu dalam aliran panas. secara kontinu variabel yang tidak diketahui ini tidak terbatas.[5]

\section{Tegangan Bending (Bengkok)}

Merupakan tegangan Merupakan tegangan yang diakibatkan oleh bekerjanya momen lentur pada benda. Sehingga pelenturan benda disepanjang sumbunya menyebabkan sisi bagian atas tertarik, karena bertambah panjang dan sisi bagian bawah tertekan, karena memendek. Dengan demikian struktur material benda di atas sumbu akan mengalami tegangan tarik, sebaliknya dibagian bawah sumbu akan menderita tegangan tekan. Sedangkan daerah diantara permukaan atas dan bawah, yaitu yang sejajar dengan sumbu benda tetap, tidak mengalami perubahan, ini disebut sebagai bidang netral.

Persamaan umum tegangan lentur, adalah :

$$
\mathrm{M}_{\mathrm{L}} / \mathrm{I}=\sigma_{\mathrm{L}} / \mathrm{y}=\mathrm{E} / \mathrm{R}
$$

\footnotetext{
Dimana :

$\mathrm{I}=$ inersia pada sumbu benda $\left(\mathrm{I}_{\mathrm{xx}}\right.$ atau $\left.\mathrm{I}_{\mathrm{yy}}\right)$.

$\mathrm{Y}=$ jarak dari bidang netral ke permukaan luar benda.

$\mathrm{E}=$ modulus elastisitas / Young.

$\mathrm{R}=$ radius kelengkungan benda
}

\section{Tegangan Torsi (Torsion Stress)}

Torsi adalah suatu pemuntiran sebuah batang yang diakibatkan oleh kopelkopel (couples) yang menghasilkan perputaran terhadap sumbu longitudinalnya. Kopel-kopel yang 
menghasilkan pemuntiran sebuah batang disebut momen putar (torque) atau momen puntir (twisting moment).[4]

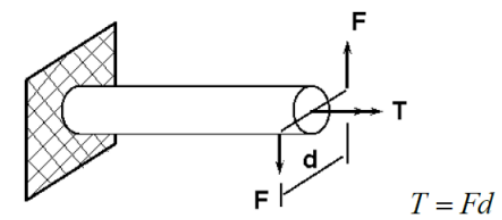

Gambar 2.1 Diagram Momen Kopel pada Batang

\section{Tegangan Puntir}

Bila sebatang material mendapat beban puntiran, maka serat-serat antara suatu penampang lintang dengan penampang lintang yang lain akan mengalami pergeseran, seperti ditunjukkan pada Gambar 2.2

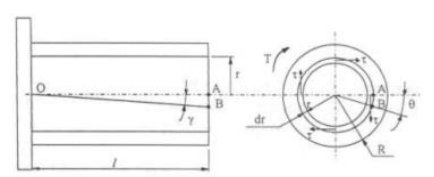

\section{Deformasi}

Gambar 2.2 Batang Silindris dengan Beban Puntiran.

Dalam ilmu material, deformasi adalah perubahan bentuk atau ukuran dari sebuah objek karena Sebuah diterapkan gaya (energi deformasi dalam hal ini ditransfer melalui kerja) atau Perubahan suhu (energi deformasi dalam hal ini ditransfer melalui panas). Deformasi terdiri dari dua bagian,yaitu deformasi elastis dan deformasi plastis.

Deformasi elastis adalah perubahan bentuk material yang apabila gaya penyebab deformasi itu dihilangkan maka deformasi kembali ke bentuk semula.[6]

\section{Regangan}

Suatu batang lurus akan mengalami perubahan panjang apabila dibebani secara aksial, yaitu menjadi panjang jika mengalami tarik dan menjadi pendek jika mengalami tekan. Sebagai contoh diperlihatkan pada Gambar 2.14, perpanjangan dari batang tersebut adalah hasil komulatif dari perpanjangan semua elemen bahan di seluruh volume batang.

$$
\varepsilon=\Delta \mathrm{L} / \mathrm{L}
$$

Dimana :

$\varepsilon \quad=$ Regangan

$\Delta L \quad=$ Pertambahan panjang

$L \quad=$ Panjang awal

\section{ANSYS Simulation}

ANSYS adalah sebuah software analisis elemen hingga dengan kemampuan menganalisa dengan cakupan yang luas untuk berbagai jenis masalah ( Tim Langlais, 1999). ANSYS mampu memecahkan persamaan differensial dengan cara memecahnya menjadi elemenelemen yang lebih kecil. Pada awalnya program ini bernama STASYS (Structural Analysis System), kemudian berganti nama menjadi ANSYS yang ditemukan pertama kali oleh Dr. John Swanson pada tahun 1970.

ANSYS merupakan tujuan utama dari paket permodelan elemen hingga untuk secara numerik memecahkan masalah mekanis yang berbagai macam. Masalah yang ada termasuk analisa struktur statis dan dinamis (baik linear dan non-linear), distribusi panas 
dan masalah cairan, begitu juga dengan ilmu bunyi dan masalah elektromagnetik. Teknologi ANSYS mekanis mempersatukan struktur dan material yang bersifat nonlinear. ANSYS multiphysic juga mengatasi masalah panas, struktur, elektromagnetik, dan ilmu bunyi. Program ANSYS dapat digunakan dalam teknik sipil, teknik listrik, fisika dan kimia.

\section{a. ANSYS Fluent}

FLUENT ialah salah satu software CFD dari ANSYS. Ansys merupakan sebuah software analisis elemen hingga (finite element), bisa dipakai untuk melakukan analisis mekanika benda tegar, analisis fluida, dan analisis perpindahan panas. Sebuah sumber mengatakan bahwa versi 12 keatas sudah kompatibel dengan Windows 7

b. Static Structural

Struktural analisis merupakan analisa yang paling banyak digunakan dengan menggunakan prinsip finite element. Struktural tidak hanya digunakan untuk struktur dalam teknik sipil seperti jembatan, gedung, tetapi meliputi unsur lain seperti kapal, pesawat, piston, dll.

Ada beberapa macam jenis simulasi static struktural, dimana pada program ansys akan terdapat perhitungan tegangan dan regangan. Static analisis digunakan untuk menentukan dan menganalisa tegangan dan menentukan displacements benda pada beban static. Static analisis dapat digunakan pada linier maupun nonlinier static analisis.

\section{METODOLOGIPENELITIAN}

Penelitian ini direncanakan berlangsung selama \pm 6 bulan. Penelitian ini dilaksanakan di Laboratorium Noise and Vibration Control program Magister dan Doktoral Teknik Mesin Fakultas Teknik Universitas Sumatera Utara

\section{Bahan dan Alat Penelitian}

Adapun bahan yang di gunakan dalam penelitiana ini adalah 1. Propeller

Propeller yang di gunakan dalam penelitian ini adalah propeler $\mathrm{Al}-\mathrm{Mg}$ yang memiliki dua bilah.

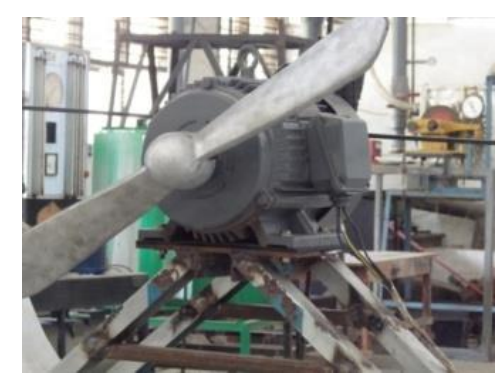

Gambar 3.1 Propeler clark y

\section{Peralatan Yang Digunakan}

Jenis peralatan yang dibutuhkan untuk analisis distribusi tegangan pada propeller UAV ini adalah sebuah laptop dengan spesifikasi sebagai berikut 
Processor : Intel Core i3

RAM : $6 \mathrm{~GB}$

CPU : $2,4 \mathrm{GHz}$

System : Windows 764 - bit

VGA : ATI Mobility Radeon

Software : Ansys 15.0

\section{Spesifikasi Data Propeller}

Pengerjaan penelitian ini memiliki spesifikasi data - data yang penting untuk proses analisa. Beberapa bentuk data yang paling dibutuhkan seperti diameter propeler, jumlah blade, tipe blade dan data lainnya telah disesuaikan dengan kajian anggota tim UAV

DIMENSI

Rentang sayap : $400 \mathrm{~mm}$

Total panjang $\quad: 800 \mathrm{~mm}$

Tinggi $\quad: 80 \mathrm{~mm}$

PROPELLER

Material Aluminium Alloys (Al-Mg)

Number of blade : 2

\section{Variabel Penelitian}

Pada penelitian ini ditentukan dua buah variable penelitian, yakni variable terikat dan variable bebas.

\section{Variabel Terikat}

Untuk menyederhanakan permasalahan dalam kajian kebisingan pada propeler, maka dalam penelitian ini ditetapkan variable terikat yakni:

1. Sudut airfoil

2. Sifat udara

3. Sifat mekanik bahan

\section{Variabel Bebas}

Variable bebas pada penelitian ini merupakan pengaruh yang diakibatkan oleh adanya variabel terikat dan ditetapkan yaitu kecepatan fluida.

\section{Spesifikasi Fluida}

Spesifikasi fluida pada saat melakukan pengujian adalah udara bebas dan juga diperlukan untuk analisi simulasidalam penelitian ini, berikut adalah properties udara :

1. Jenis Fluida: Udara atmosfer

2. Tekanan Fluida: $101325 \mathrm{~Pa}$

\section{ANALISA DATA}

Pada pengujian simulasi dilakukan pengujian Fluent (aliran) guna mendapatkan aliran udara yang terjadi pada propeller.

\section{Hasil Pengujian Fluent}

Pada pengujian simulasi dilakukan pengujian Fluent (aliran) guna mendapatkan aliran udara yang terjadi pada propeller. 


\section{Deformasi}

a. Kecepatan $10 \mathrm{~m} / \mathrm{s}$

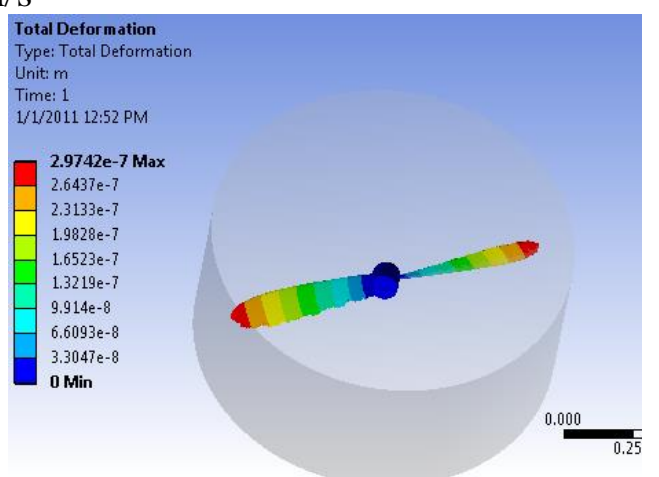

b. Kecepatan $20 \mathrm{~m} / \mathrm{s}$

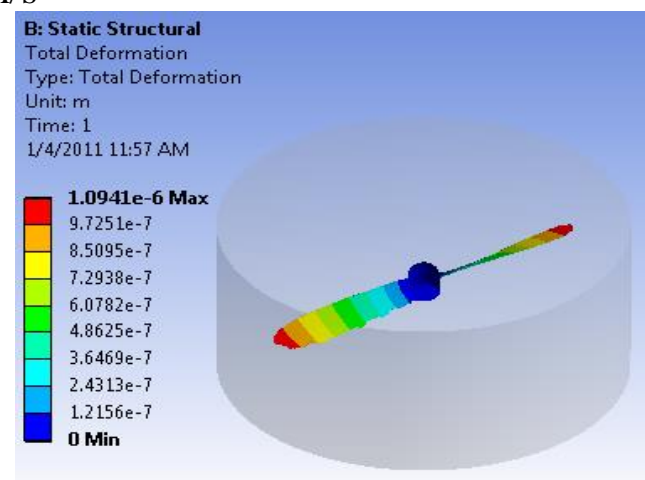

c. Kecepatan $30 \mathrm{~m} / \mathrm{s}$



d. Kecepatan $40 \mathrm{~m} / \mathrm{s}$ 


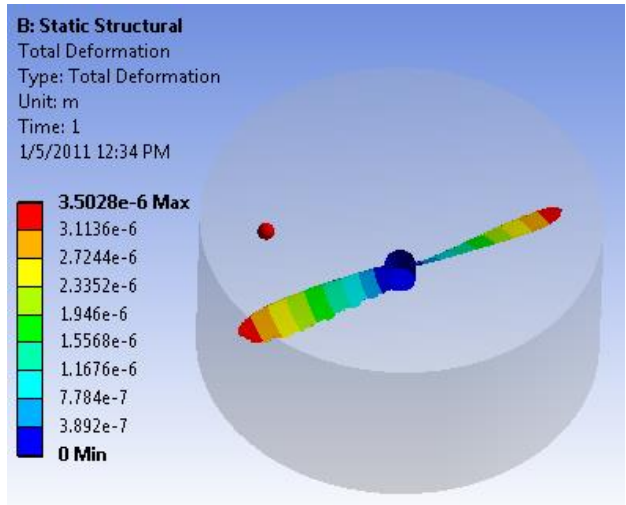

e. Kecepatan $50 \mathrm{~m} / \mathrm{s}$



Dari deformasi yang terjadi dapat dilihat bahwa total deformasi maksimum pada propeller terjadi pada ujung blade propeller. Pada gambar diatas, terlihat perbedaan warna pada bilah propeller. Ujung propeller memiliki kontur warna merah. Ini berarti yang mengalami perubahan bentuk terakhir ialah ujung propeller tersebut. Perubahan bentuk yang pertama terjadi adalah pangkal propeller yang melekat pada hub.kecepatan fluida $10 \mathrm{~m} / \mathrm{s}$ adalah sebesar $2.9742 \times 10^{-7} \mathrm{~m}$, kecepatan fluida $20 \mathrm{~m} / \mathrm{s}$ adalah sebesar $1.0941 \times 10^{-6} \mathrm{~m}$,

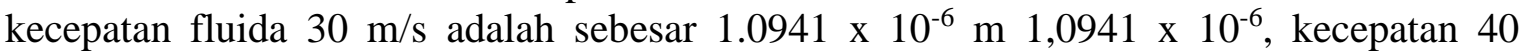
sebesar $3.2028 \times 10^{-6}$, kecepatan 50 sebesar $5.0521 \times 10^{-6}$.

\section{Regangan}

a. Kecepatan $10 \mathrm{~m} / \mathrm{s}$



b. Kecepatan $20 \mathrm{~m} / \mathrm{s}$ 


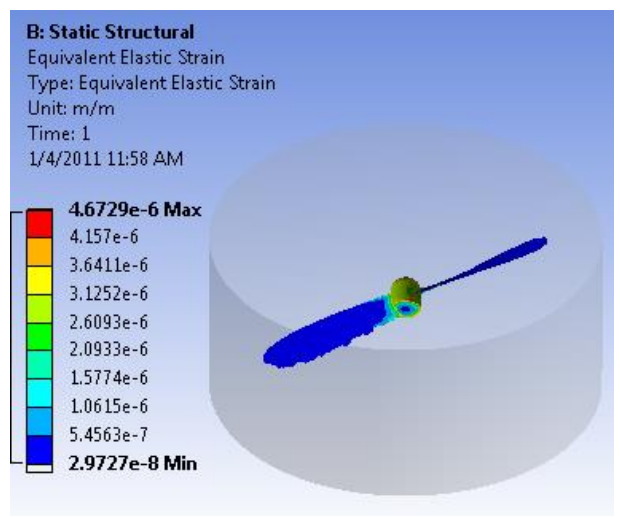

c. Kecepatan $30 \mathrm{~m} / \mathrm{s}$



d. Kecepatan $40 \mathrm{~m} / \mathrm{s}$

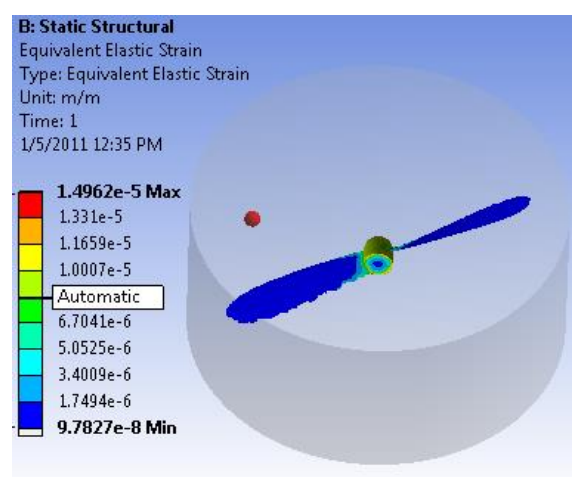

e. Kecepatan $50 \mathrm{~m} / \mathrm{s}$

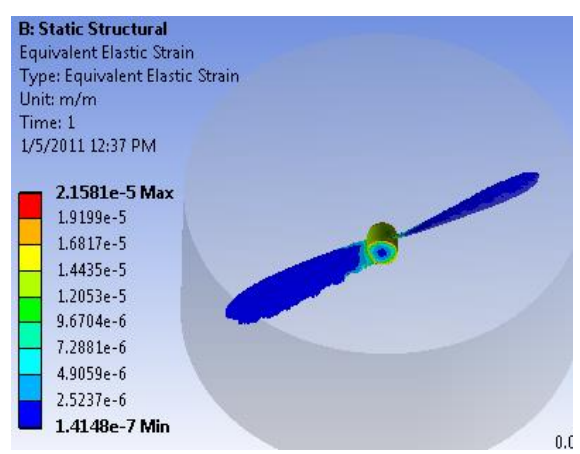

Dari hasil deformasi yang terjadi dapat dilihat bahwa regangan maksimum pada kecepatan fluida $10 \mathrm{~m} / \mathrm{s}$ adalah sebesar $1.2676 \times 10^{-6} \mathrm{~m} / \mathrm{m}$, kecepatan $20 \mathrm{~m} / \mathrm{s}$ sebesar $3.157 \times 10^{-6}$, 
kecepatan $30 \mathrm{~m} / \mathrm{s}$ sebesar $4.6729 \times 10^{-6}$, kecepatan $40 \mathrm{~m} / \mathrm{s}$ sebesar $1.4967 \times 10^{-5}$, kecepatan $50 \mathrm{~m} / \mathrm{s}$ sebesar $2.1581 \times 10^{-5}$,

\section{Tegangan}

a. Kecepatan $10 \mathrm{~m} / \mathrm{s}$

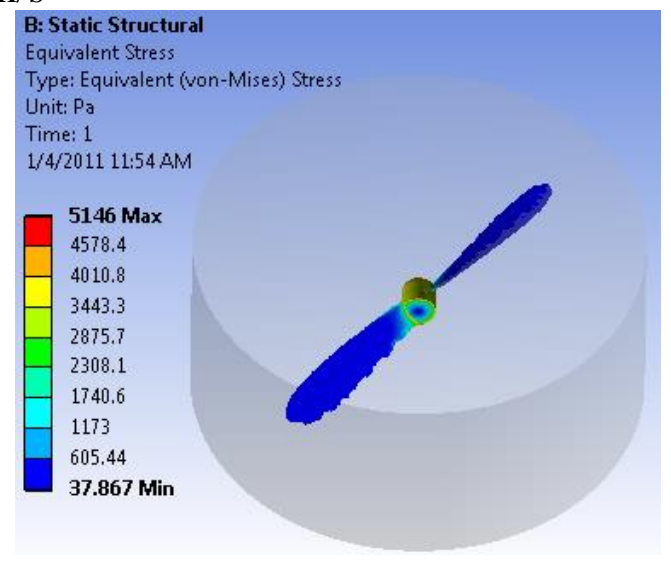

b. Kecepatan $20 \mathrm{~m} / \mathrm{s}$

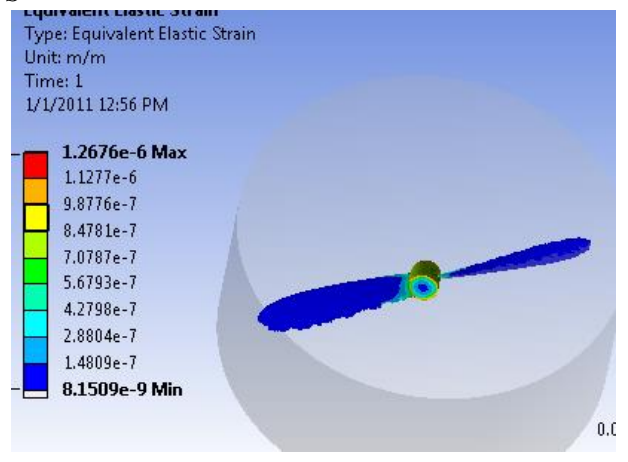

c. Kecepatan 30 m/s

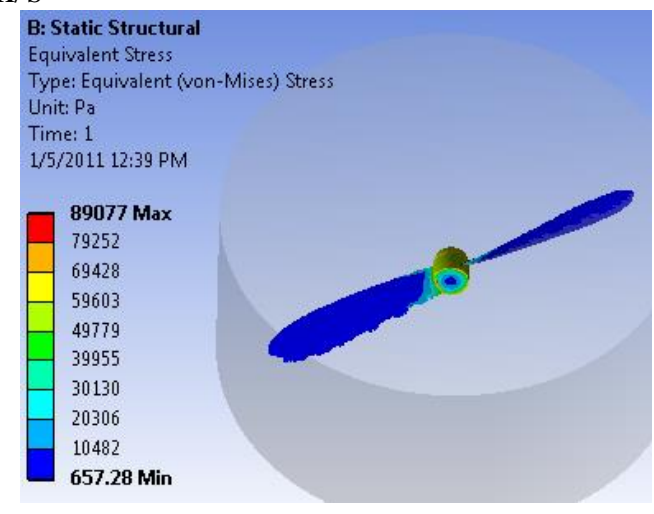

d. Kecepatan $40 \mathrm{~m} / \mathrm{s}$ 


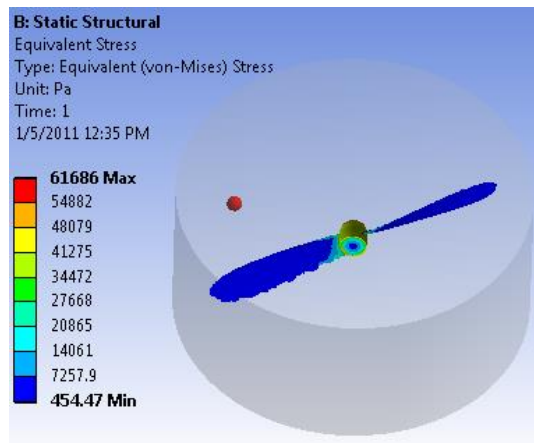

e. Kecepatan $50 \mathrm{~m} / \mathrm{s}$



Dasi hasil pengujian dapat dilihat bahwa tegangan maksimum bagian sambungan propeller pada kecepatan fluida $10 \mathrm{~m} / \mathrm{s}$ adalah sebesar $51.46 \mathrm{~Pa}$, kecepatan $20 \mathrm{~m} / \mathrm{s}$ sebesar $1.2676 \mathrm{x}$ $10^{-6} \mathrm{~Pa}$, kecepatan $30 \mathrm{~m} / \mathrm{s}$ sebesar $89077 \mathrm{~Pa}$, kecepatan $40 \mathrm{~m} / \mathrm{s}$ sebesar $61606 \mathrm{~Pa}$, kecepatan $50 \mathrm{~m} / \mathrm{s}$ sebesar $89077 \mathrm{~Pa}$

\section{KESIMPULAN DAN SARAN}

\section{Kesimpulan}

Dari hasil analisa data simulasi maka didipatkan tiga hasil kesimpulan sebagai berikut :

1. Semakin tinggi laju aliran fluida pada propeller maka tegangan yang terjadi pada bilah propeller semakin besar. Dimana tegangan terendah berada pada kecepatan $10 \mathrm{~m} / \mathrm{s}$ dengan nilai $51.46 \mathrm{~Pa}$, dan tegangan tertinggi pada kecepatan $50 \mathrm{~m} / \mathrm{s}$ dengan nilai $89077 \mathrm{~Pa}$

2. Total deformasi yang paling besar pada kecepatan $10 \mathrm{~m} / \mathrm{s}-50 \mathrm{~m} / \mathrm{s}$ adalah pada bagian ujung bilah propeller dengan nilai minimum sebesar $2.97 \times 10^{-7} \mathrm{~m}$ dan nilai deformasi maksimum pada kecepatan $50 \mathrm{~m} / \mathrm{s}$ sebesar $5.0521 \times 10^{-6}$.

3. Regangan yang paling besar pada propeller terdapat pada bagian hub propeller dengan nilai regangan minimum sebesar $1.2676 \times 10^{-6}$ dan2.1581 x $10^{-5}$ nilai regangan maksimum pada $50 \mathrm{~m} / \mathrm{s}$ sebesar $2.1581 \times 10^{-5}$.

\section{Saran}

Adapun saran yang diberikan pada penelitian selanjutnya adalah sebagai berikut:

1. Meakukan uji simulasi yang sama dengan menggunakan propeller 4 blade

2. Lebih teliti dalam memasukkan nilai spesifikasi fluida pada software ansys $\mathbf{1 5 . 0}$

3. Menggunakan paduan material yang lebih kuat dan elastis

\section{DAFTAR PUSTAKA}


[1] Anderson Jr, Jhon D. 1999 . Fundamental of Aerodyamics. Boston : Mc.Graw-Hill.

[2] Ardhianto , Kurniawan. 2011. Desain dan Analisis Propeller pada Unmanned Aerial Vehicle $(U A V)$. AAU Journal of Defense Science and Technology Volume 2, Number 1, 1 July 2011, $125-133$.

[3] Barron,Randall F. 2001. Industrial Noise Control and Acoustics. New-York. :Marcel Dekker, Inc

[4] Clancy,L.J 1975. Aerodynamics. London : Pittman Publishing Limitted

[5] JR, William Weaver and Paul R. Johnston. 1993. Elemen Hingga Untuk Analisis Struktur. Bandung : Eresco

[6] Omotoyinbo,J.,A dan Oladele,I.,O, 2010, "The Effect of Plastic Deformation and Magnesium Content on the Mechanical Properties of 6063 Aluminium Alloys", Journal of Minerals \& Materials Characterization \& Engineering, Vol.9, No.6, pp.539.546, USA. 